\title{
Miscommunication Of Uncertainties In Financial Statements: A Study Of Preparers And Users
}

Kim Capriotti, (E-mail: kcaprio@ju.edu) Jacksonville University

Bobby E. Waldrup, (E-mail: bwaldrup@unf.edu), University of North Florida

\begin{abstract}
The focus of this study is management's communication of uncertainty (attested to by auditors) and the potential for miscommunication due to the communication mode used in accounting disclosures. Two hypotheses are addressed to determine if financial statement users differentiate among three levels of uncertainty (using SFAS No. 5 as a vehicle for study), and whether their judgments differ when numerical probabilities replace the prescribed verbal expressions in communicating these uncertainties. The participants for this study are drawn from commercial loan officers from a major regional bank. Results lend evidence that both the level of uncertainty and the mode of communication are significant factors influencing the level of risk revision in an uncertainty exercise. Support is found that miscommunication may exist between the preparers and users of financial statements. However, support is not found that the "vagueness" of SFAS No. 5 verbal expressions of uncertainty is detrimental to users' decision-making abilities.
\end{abstract}

\section{INTRODUCTION}

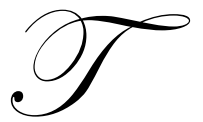

his study investigates the interpretation and use of verbal ${ }^{1}$ and numerical expressions of probability by commercial loan officers. When assessing the riskiness of companies' loan applications, loan officers rely on financial statement information, including the disclosure of uncertainties. The focus of this research is the communication of uncertainty by management (and attested by auditors) and the potential for miscommunication due to the disclosure mode utilized. Specifically, two questions are addressed: First, do users of financial statements differentiate among the three levels of uncertainty as expressed in SFAS No. 5 (Accounting for Contingencies)? Second, are there differences in users' judgments (i.e., risk assessments) when numerical probabilities replace verbal expressions in communicating these uncertainties?

Managers are required to communicate uncertainties in the prescribed manner of SFAS No. 5. In effect, the audit profession establishes a frame that may be differentially interpreted by users of the financial statements. A problem arises if the verbal expressions required by SFAS No. 5 would cause different cognitive judgments or actual financial decisions than the use of the "equivalent" numerical probability. If the frame of expressions used to communicate uncertainty does not allow for uniform understanding, the likelihood of inconsistencies in users' interpretations may be increased.

\section{LITERATURE REVIEW}

SFAS No. 5, an authoritative pronouncement of the Financial Accounting Standards Board, directs auditors in the evaluation of management's disclosure of uncertain events. The Statement employs the verbal expressions, "remote", "reasonably possible", and "probable" to identify three levels of uncertainty regarding the likelihood of a loss due to future events. Per SFAS No. 5 these levels are defined as: 
Probable:

Reasonably possible:

Remote:
The future event or events are likely to occur.

The chance of the future event or events occurring is more than remote but less than likely.

The chance of the future event or events occurring is slight.

Within the SFAS No.5 definitions, these three terms are defined using other verbal expressions of uncertainty (likely and slight) to describe the likelihood of the future events occurring. Past research in this area (See, for example, Schultz and Reckers 1981; Jiambalvo and Wilner 1985; Harrison and Tomassini 1989; Beaver 1991; Raghunandan et al. 1991; Reimers 1992; Tarek et al. 1994; and Nelson \& Kinney 1997, for a chronological paradigm stream.) indicates that auditors disagree on thresholds and often have narrowly defined numerical probability ranges for each verbal expression from SFAS No. 5, which in turn, may not correspond to meanings assigned these terms by financial statement users.

SFAS 5 was chosen to operationalize this experiment. While the financial accounting profession is replete with instances of information framing, this pronouncement is an attractive vehicle of study for several reasons. First, SFAS 5 is well researched, and has been found to impact financial decisions (again, see aforementioned research stream in the preceding paragraph). The pronouncement contains specific verbal expressions (i.e. framing mechanism) that do not require experimenter alteration. Finally, certain sophisticated financial statement users (in this case, bank loan officers) are highly risk adverse, and are specifically trained to search for instances of uncertainty in financial statements.

\section{VERBAL EXPRESSIONS AND NUMERICAL PROBABILITIES}

Early psychology literature focused upon the use and interpretation of verbal expressions, beginning with Simpson $(1944,1963)$, who found high degrees of variability in interpretation for 20 common verbal expressions. The issue of whether people think and communicate more effectively using verbal or numerical expressions has received more contemporary attention (Beyth-Marom 1982; Kong et al. 1986; Wallsten et al. 1986). Zwick (1987) summarizes this research by concluding that verbal expressions of probability may be preferable, but are less precise than numerical communication. Extending this reasoning, a policy of using verbal rather than numerical probabilities has been criticized by several authors (Beyth-Marom 1982; Nakao and Axelrod 1983; Hamm 1991) as comparing separate, and only arguably equal, constructs. Budescu, Weinberg, and Wallsten (1988) supported this literature with the observation that individuals interpret verbal expressions of uncertainty as ambiguous numerical probabilities. Recently, Teigen and Brun (1999, 155) expressed concerns about this literature, concluding that "verbal probabilistic phrases differ from numerical probabilities not primarily by being more 'vague,' but by suggesting more clearly the kind of inferences that should be drawn."

By recognizing that most verbal phrases are unidirectional (either an upward or downward focus), their findings suggest that it is the directionality of verbal phrases that most influences the conclusions users draw from communication about uncertain outcomes leading to strong framing effects.

\section{FRAMING AND PRESENTATION MODE IN AUDIT ISSUES}

The "framing" effect, identified by Kahneman and Tversky (1984) and Tversky and Kahneman (1981, 1986) indicates that judgments may be influenced by the language used to elicit those judgments (Emby 1994). The context of framing in an audit environment has been examined in the areas of financial statement analysis (Jamal et al. 1995), going concern judgments (Trotman and Sng 1989; Asare 1992), substantive testing (Emby 1994), and managerial accounting decisions (Chang et al. 2002), with studies consistently demonstrating that auditors and other accountants are influenced by situation framing effects.

According to Kahneman and Tversky's (1979) prospect theory, the frame will put a user into a "gain" or "loss" domain in a given situation (see Dusenbury \& Fennema, 1996, for a complete discussion of the relationship between gain/loss decisions and presentation modes). Extrapolating that the Kahneman and Tversky S-shaped value function is concave for gains and convex for losses (i.e., losses loom larger than gains), Emby (1994) found that 
auditors perceive risks to be higher when presented with greater uncertainty, more fearful of a type II error than a type I error.

Sophisticated users of financial statements are also affected by the need to avoid type II errors. Recent research in the area of bank lending has focused on the cognitive processes that lending officers use in evaluating loan applicants (Stocks and Tuttle 1998; Danos et al. 1989; Deitrick and Stamps 1981; Libby 1979), confirming that framing may also affect these user groups.

\section{RESEARCH DESIGN AND METHODOLOGY}

The research model tested in this study is:

Change in Risk Assessment $\boldsymbol{f}$ level of uncertainty + mode of communication $+\mathbf{\epsilon}$

where,

level of uncertainty $=\quad$ three levels of uncertainty (of a new contingency) as defined by SFAS No. 5, and mode of communication $=$ two levels of data presentation, either numerical or verbal expressions.

The research model stems from the two research questions and forms the basis for the two hypotheses. The first hypothesis addresses the first research question: Do commercial loan officers (sophisticated financial statements users) differentiate among the three levels of uncertainty, when communicated either by the three verbal expressions from SFAS No. 5 or by the corresponding numerical probability ranges in the appropriate order. Hypothesis 1 (stated in alternative form) also suggests that disclosure of material uncertainties is important for lending decisions.

H1: The level of uncertainty, communicated as verbal or numerical expressions, will differentially affect the risk assessments (cognitive judgments) of commercial loan officers.

The second hypothesis stems from the second research question -- does there exist differences in users' decisions or judgments when numerical probabilities replace verbal expressions in communicating these uncertainties? According to the theory of judgment and choice based on linguistic uncertainties (see Budescu et al. 1988 for a full discussion) verbal phrases are "linguistic variables" that can be represented by a membership function $^{2}$ over the $(0,1)$ interval of numerical probabilities. This theory describes verbal expressions as resulting in more extreme judgments than numerical probabilities. The use of the word "extreme" refers to direction, either positive or negative, based on the framing of the judgment or decision. For example, if a judgment is framed negatively, then the judgment made using the verbal expression will be more negative than the judgment made using the numerical probability expression. In this experiment, risk assessments are framed negatively, so more extreme means riskier.

Stocks and Tuttle (1998) indicate that financial accounting data is commonly displayed in both numeric and categorical formats, and the presentation method may affect user's decision insight. Accordingly, hypothesis 2, stated in alternative form, is:

H2: Judgments of the risk level, i.e., riskiness, of a loan applicant based on uncertainty information disclosed through verbal expressions will be different than those based on equivalent information disclosed numerically.

The test of hypothesis 1 -- that risk assessments by the commercial loan officers vary as a function of the level of uncertainty -- was tested by examining the main effect for level of uncertainty. The test of hypothesis 2 -that judgments of the risk level of a loan applicant based on verbally expressed uncertainty will be different than those based on numerically expressed uncertainty -- was tested by examining the main effect of communication mode. Apriori, we find no theory to support the existence or absence of an interaction; therefore, no formal hypothesis was stated regarding an interaction effect. 


\section{PARTICIPANTS}

The participants were selected from the offices of a major regional bank. Through a contact person with this regional financial institution, nine contact persons in nine different cities volunteered to coordinate the distribution and collection of the experimental instrument. A total of 190 experimental instruments were mailed, along with a cover letter asking them to distribute the instrument to commercial loan officers, commercial credit analysts, and vice-presidents in the commercial area. The contact person made a follow-up request after one month. The contact in each of the nine cities collected the completed instruments and mailed them back in pre-paid postage envelopes. Prior to the cut-off date, 81 usable and completed experimental instruments were received.

\section{EXPERIMENTAL TASK}

The experiment consisted of a brief scenario (Appendix) in which the loan officers received a description of the financial position of a typical manufacturing company seeking approval for a loan.

The company description was provided as the basis for an initial judgment regarding the risk level of the company. After making the initial judgment, each loan officer was given additional uncertainty information (contained in the financial statements) regarding a loss contingency. After receiving this additional information, participants were asked to revise their judgments regarding the risk level of the company. The nominal initial judgment was used as the anchor from which to standardize the revised judgments of the participants in the creation of the dependent variable.

The sequence of information given to the participants follows Hogarth and Einhorn (1992) step-by-step ( $\mathrm{SbS}$ ) model of belief updating. The model predicts that evidence evaluated sequentially results in a more extreme judgment than the evidence evaluated simultaneously. In algebraic terms the model presented to the participants was in the form:

$\mathrm{S}_{\mathrm{k}}=\mathrm{S}_{\mathrm{k}-1}+\mathrm{W}_{\mathrm{k}}\left(\mathrm{s}\left(\chi_{\mathrm{k}}\right)-\mathrm{R}\right)$

where,

$\mathrm{S}_{\mathrm{k}} \quad=$ strength of belief in some hypothesis, event, etc., after evaluating k pieces of evidence $\left(0 \leq \mathrm{S}_{\mathrm{k}} \leq 1\right)$.

$\mathrm{S}_{\mathrm{k}-1} \quad=$ anchor or prior opinion (after evaluating the $\mathrm{k}-1$ th piece of evidence). The initial strength of belief is denoted $\mathrm{S}_{0}$.

$\mathrm{W}_{\mathrm{k}} \quad=$ the adjustment weight for the kth piece of evidence.

$\mathrm{s}\left(\chi_{\mathrm{k}}\right) \quad=$ subjective evaluation of the kth piece of evidence.

$\mathrm{R}=$ the reference point or background against which the impact of the kth piece of evidence is evaluated.

The dependent variable is the change in risk assessment, which is defined as the difference between the revised risk assessments made by the loan officers after they received the uncertainty information and their initial risk assessment made before they received the uncertainty information.

As shown in the Appendix, the participants indicated their risk assessments on a continuum rather than a prenumbered likert scale. This assessment method was utilized for two reasons. First, the numerical nature of a likert scale might have inadvertently biased the participants' risk assessments in this particular task. Second, the risk assessment on a continuum scale mimics the actual methodology employed by the regional bank from which the participant pool was drawn.

Three levels of uncertainty, defined by SFAS No. 5, and two modes of communication, numerical and verbal, were manipulated between participants. The three levels of uncertainty, in terms of the verbal expressions, were remote, reasonably possible, and probable. The corresponding numerical probability ranges were the mean ranges reported in Reimers $(1992)^{3}$, rounded to the nearest increment of ten, excluding the endpoints, 0 and 100. The following ranges were used: remote: $10 \%$ to $20 \%$, reasonably possible: $50 \%$ to $70 \%$, probable: $70 \%$ to $90 \%$. 
Although auditors determined these ranges, there is reason to believe commercial loan officers' numerical probability ranges would be similar. Commercial loan officers, like auditors, are conservative and seek to reduce their type II errors, i.e., the approval of a loan applicant who later defaults. The two hypotheses were investigated using a $3 \times 2$ (Level of Uncertainty by Mode of Communication) full factorial design with both variables manipulated between-participants, illustrated in figure 1. Each participant received one loss contingency scenario, containing either a verbal expression or numerical probability range for one level of uncertainty.

FIGURE 1 Factorial Design of Study

\begin{tabular}{|c|c|c|c|}
\hline Mode Of Communication & \multicolumn{3}{|c|}{ Level Of Uncertainty } \\
\hline & Low & Middle & High \\
\hline Verbal & Remote & Reasonably Possible & Probable \\
\hline Numerical & $10 \%$ to $20 \%$ & $50 \%$ to $70 \%$ & $70 \%$ to $90 \%$ \\
\hline
\end{tabular}

\section{EXPERIMENTAL CONTROL}

As shown in the Appendix, a multi-part post-experimental questionnaire was presented to the participants. This questionnaire was utilized in order to determine the effectiveness of the experimental manipulations in this study. Specifically, the following three questions were assessed: (1) Did the participants translate the SFAS No. 5 verbal expressions of uncertainty to the numerical probability ranges used in this study? (2) Did the loan officers appear to be previously aware of the accounting standard, SFAS No. 5, which was being experimentally manipulated between participants? (3) Did the participants' demographics drive the study's results?

In section one, the participants were asked to mark the two endpoints on a scaled line that they believed identified the numerical probability range for each verbal expression of uncertainty listed (nine verbal expressions), including the three expressions used in this study -- remote, reasonably possible, and probable. The following were the average numerical probability ranges across all of the participants: remote: $5 \%$ to $17 \%$, reasonable possible: $50 \%$ to $69 \%$, probable: $66 \%$ to $85 \%$. These ranges are very similar to the ranges used in this study as translations of the verbal expressions. This provides evidence that the ranges selected for this study were congruent with loan officers' beliefs.

The second section included questions to help determine whether the participants were aware of the accounting standard, SFAS No. 5, Accounting for Contingencies. Specifically, they were asked to select the phrase (from a list of five) that best defined each of the verbal expressions contained in the Standard. The phrase list was randomized between participants to avoid order effects. The technical SFAS No. 5 definition was chosen by only $61 \%$ of the loan officers for remote, $32 \%$ for reasonably possible, and $18 \%$ for probable. Therefore, it is reasonable to conclude that the loan officers in this study were, on average, unencumbered by specific previous knowledge of the accounting standard SFAS No. 5 or the technical meaning of the three expressions, and hence, did not view these three manipulated verbal expressions to be special or different from other verbal expressions.

In the final section, demographic information was elicited including age, gender, years of experience as a commercial loan officer, average number of loans processed per year, typical dollar amount of loan processed, highest education level achieved, and position/title at the financial institution. The commercial loan officers in this study came from very diverse backgrounds with respect to age, years of experience, and average number of loans processed. In spite of this wide range of diversity among the participants, a subsequent ANCOVA estimate indicates that none of these demographic variables are significant covariates to the constructs of study.

\section{RESULTS}

Table 1 presents summary data of the means, standard deviations, and number of observations for the dependent variable - change in risk assessment. 
TABLE 1 Cell Means (And Standard Deviations) For the Change in Risk Assessment

\begin{tabular}{|c|c|c|c|c|}
\hline \multirow[t]{2}{*}{ Mode Of Communication } & \multicolumn{4}{|c|}{ Level Of Uncertainty } \\
\hline & Low & Middle & High & \\
\hline Verbal & $\begin{array}{c}.36 \\
(.732) \\
\mathrm{N}=12\end{array}$ & $\begin{array}{c}1.43 \\
(1.045) \\
\mathrm{N}=16\end{array}$ & $\begin{array}{c}.66 \\
(.922) \\
\mathrm{N}=13\end{array}$ & .87 \\
\hline Numerical & $\begin{array}{c}.90 \\
(.732) \\
\mathrm{N}=13\end{array}$ & $\begin{array}{c}1.80 \\
(.925) \\
\mathrm{N}=13\end{array}$ & $\begin{array}{c}1.43 \\
(.820) \\
\mathrm{N}=14\end{array}$ & 1.38 \\
\hline & .64 & 1.60 & 1.06 & \\
\hline
\end{tabular}

As expected, the cell mean for the numerical mode (1.38) was significantly different than for the verbal mode (.87). As explored in the discussion of results section that follows, the cell means for the three levels of uncertainty did not behave in the hypothesized order. As shown in table 2, both main effects are statistically significant at the .05 level.

TABLE 2 Analysis of Variance Using the Change in Risk Assessment as the Dependent Variable

\begin{tabular}{|l|c|c|c|c|}
\hline Source & Sum of Squares & DF & Mean Square & F \\
\hline Main Effects & 18.763 & 3 & 6.254 & $7.128^{*}$ \\
\hline Level of Uncertainty & 13.588 & 2 & 6.794 & $7.743^{*}$ \\
\hline Mode of Communication & 6.252 & 1 & 6.252 & $7.125^{*}$ \\
\hline \multicolumn{7}{|l|}{} \\
\hline Two-way Interaction & .551 & 2 & .276 & .314 \\
\hline Residual & 65.807 & 75 & .877 & \\
\hline \multicolumn{3}{|l}{} \\
\hline$*$ significant at p-value of $<.05$ &
\end{tabular}

Accordingly, both hypotheses are supported, lending evidence that both the level of uncertainty and the mode of communication are significant factors in loan officers' change in risk assessments due to loss contingencies. The interaction term was not significant, and thus is excluded from further discussion.

\section{DISCUSSION OF RESULTS}

While both of the study's main effects (level of uncertainty and mode of communication) were significant predictors of loan officers' change in risk assessments, it is interesting that, directionally, the results did not follow apriori expectations.

\section{Level of Uncertainty}

In the test of hypothesis 1 -- the level of uncertainty will differentially affect the risk assessments of commercial loan officers -- the main effect for the level of uncertainty was significant, but the means for each of the three uncertainty levels did not behave in the hypothesized (or expected) order of low, middle, and high uncertainty (see table 1). The low level (corresponding to the verbal expression "remote" and the numerical probability range " $10 \%$ to $20 \%$ ") and the high level (corresponding to the verbal expression "probable" and the numerical probability range " $70 \%$ to $90 \% ")$ were significantly lower than the middle level (corresponding to the verbal expression "reasonably possible" and the numerical probability range "50\% to $70 \%$ "), with p values of .004 and .08, respectively. However, changes in the risk assessments for the low level and the high level did not significantly differ $(\mathrm{p}$ value $=.498)$. 
In post-experimental phone interviews, we asked for potential explanations for these results. A (nonrandomized) sample of the loan officers indicated an assumption that for the high level of uncertainty corresponding to the verbal expression "probable" and the numerical probability range " $70 \%$ to $90 \%$ ", some of the loan officers assumed that the loss from the pending litigation had been booked (i.e., included in the financial statements), or at least widely anticipated by stakeholders. Thus, for the high level of uncertainty, the likelihood of losing the pending litigation is more anticipated. In other words, in the mind of the loan officer the uncertainty is actually reduced as the likelihood of losing the pending litigation increases. In retrospect, these findings are supported by the aforementioned unidirectional theory presented by Teigen and Brun (1999).

\section{Mode of Communication}

The test of hypothesis 2 -- judgments of the risk level of a loan applicant based on verbally expressed uncertainty will be different than those based on numerically expressed uncertainty -- was tested by examining the main effect for the mode of communication construct. This main effect was significant, and the means for the two modes of communication show that the mean change in risk assessment for the numerical probability ranges was statistically higher than the mean change in risk assessment for the verbal expressions ( $\mathrm{p}$-value $=.009$ ).

Across all three levels of uncertainty, the commercial loan officers in this study reacted more strongly to numerical cues than verbal ones. ${ }^{4}$ By moving a shorter distance off their initial risk assessment anchor, the participants under-reacted to the equivalent information received verbally. Given that our experimental scenario provides for no objective solution, we can only conclude that as a sub-set of financial statement users, commercial loan officers are, at least cognitively, differentially affected by the communication mode of uncertainties.

\section{Relationship of the Revised Risk Assessments to the Loan Decision}

The final question posed to the commercial loan officers in the instrument (Appendix) asked them to determine whether or not they would grant the loan to Company $\mathrm{X}$, given the risk information presented. The risk assessment value of 2.44 (the scale for this variable was from 0 , corresponding to "riskless", to 5.0, corresponding to "exceeds maximum risk allowance") was the dividing point between the yes and no loan decision. Of the useable surveys, $78 \%$ of the loan officers indicated a risk assessment higher than the 2.44 threshold. Correspondingly, $80 \%$ of those respondents refused to grant the loan. From this data, we find that the revised risk assessment (given after the participants received information on the loss contingency for a fictitious company) was statistically related to the loan decision (one-tail $\mathrm{p}$-value $=.0179$ ), using the nonparametric runs test.

While the risk assessment was found to significantly predict the overall loan decision, table 3 illustrates little difference in the participants' loan decisions across treatments.

TABLE 3 Cell Means (And Standard Deviations) For Participants' Loan Decisions

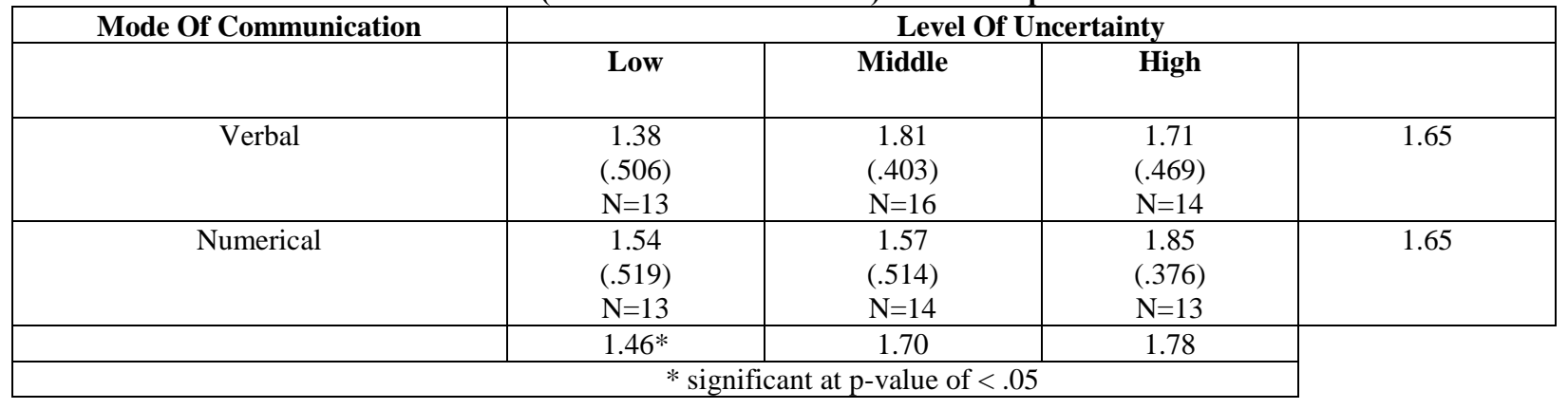

An ANOVA estimate confirms that a significant main effect for the level of uncertainty (p-value $=.042)$ as expected but no difference between the two modes of communication $(p$-value $=.967)$ and no interaction $(p$-value $=$ 
.204). This result indicates that no evidence could be found that a relationship exists between the ultimate loan decision and the mode of communication in this experimental context.

\section{CONCLUSION}

There are three points that can summarize the results of this study. First, the level of uncertainty (low, middle, high) and the mode of communication (verbal and numerical) main effects were found to be significant predictors of the difference between the initial risk assessment and the revised risk assessment (risk revision). The interaction between the two factors was not significant. Second, although the two main effects were significant, the means for each of these factors did not exactly behave as expected. For the level of uncertainty factor, the middle level mean (risk revision $=1.60$ ) was found to be significantly higher than both the low (risk revision $=.64$ ) and high (risk revision $=1.06$ ) level means. For the mode of communication factor, risk revision was significantly higher for participants given the numerical cues (1.38) than those given the verbal cues (.87). Third, there exists a significant relationship between the revised risk assessment and the ultimate decision to grant or deny the loan, but no such relationship can be established between the mode of communicating the uncertainty and the loan decision.

\section{DISCUSSION}

The primary implication from the results presented is that commercial loan officers give more conservative risk assessments (assess a higher level of risk) for a loan applicant when uncertainty information is communicated by numerical probability ranges rather than with the equivalent verbal expressions. Since this group of loan officers was extremely concerned about granting loans that would not be repaid (average of 4.35 on a scale to 5.0, where the scale was from 0 , corresponding to "not at all concerned", to 5.0, corresponding to "extremely concerned"), the use of numerical probabilities to communicate uncertainties could result in more conservative risk assessments. The implication of this result on financial reporting policy is that the choice of either numerical probabilities or verbal expressions to communicate uncertainties does differentially affect the cognitive processes employed to render a decision of granting or denying loans.

A second but related implication centers on the mode of communication of uncertainty and the ultimate decision to grant or deny a loan. While the cognitive processes of loan officers do appear to be affected by communication mode, no direct connection could be made between the mode employed and the ultimate loan decision in this case. Rest's (1984) Four Component Model of reasoning illustrates that, a decision maker progresses through the stages of Perception, Judgment, Intention, and finally Behavior, showing that cognitive judgments are at least one step removed from actual behavior. As explained by Armstrong (1987), a person may employ a broad spectrum of cognitive judgments to arrive at a given decision (behavior). However, when that decision is constrained by a $0 / 1$ solution, the connection between judgments and decisions can become immeasurable. In this study, we find this same phenomenon; where loan officers' judgments are affected by the communication mode, but the ultimate decision is not noticeably altered. Thus while differentially affective, we find no evidence to support the argument that the "vagueness" of SFAS No. 5 verbal expressions of uncertainty is ultimately detrimental to financial statement users.

Since this study found that a difference in judgment exists as a result of using numerical probabilities versus verbal expressions to convey uncertainty, auditors and financial statement users should consider these results when using decision models in which uncertainty information is input. More research needs to be conducted in this area to determine if uncertainties communicated using numerical probabilities produce more conservative outcomes in all judgment situations.

A final implication of this study relates to the issue of the level of uncertainty. This study found that one group of financial statement information users (commercial loan officers) did not perceive the verbal expressions in the appropriate order as defined in SFAS No. 5. The loan officers differentiated among the three verbal expressions of uncertainty, but not in the same order as the providers of this information expected. This result is of most immediate practical significance. It supports the current belief that some miscommunication exists between the providers and users of financial statement information. 


\section{FUTURE RESEARCH}

This area of research is rich for potential future studies. The investigation of other user groups' interpretations of the verbal expressions of uncertainty from SFAS No. 5 is needed to place these results in perspective. The use of verbal expressions to communicate uncertainty can also be examined in other accounting areas, e.g., prospective financial statements. Further, the interpretation of verbal expressions of uncertainty should be compared between user groups and auditors to investigate potential differences between groups' perceptions of specific financial statement information. Finally, investigation should be extended to differences among users in interpreting verbal and numerical probabilities in other auditing related items where uncertainty information is communicated, i.e., president letter, audit opinion, footnotes.

\section{APPENDIX}

\section{General Instructions}

On the following pages, you will be given a few paragraphs describing Company $\mathrm{X}$, which is applying for a loan at your bank. While actual loan decisions are made with more information than that provided in the paragraphs, please use only the information given to respond to the questions.

Please answer all questions to the best of your ability, leaving no questions unanswered. There are no right or wrong answers. All participants will remain anonymous, and all responses will be confidential. Please do not write your name anywhere on the packet materials. Please proceed through the materials in the order given and do not go back to previous sections and change your answers.

A medium-sized manufacturing company (named Company $\mathrm{X}$ ) has come to your bank for a short-term loan. The current loan amount Company $\mathrm{X}$ has requested is in the average size range for your bank and is consistent with Company X's past borrowing from your bank. The company has always been financially strong and never had problems with payback. Company $\mathrm{X}$ is in a stable industry, which is not affected by recessionary conditions.

In lieu of financial statement information, you are told that Company $\mathrm{X}$ has been, in previous years, ranked in the highest category for both the timeliness and safety factors (financial strength measures) by Value Line. Also Company X's Z-score (per the Altman Bankruptcy Model) indicates a classification with the healthy firms (not predicted to go bankrupt).

Although, actual loan decisions are made with much more information than that provided in this scenario, use only the information above and mark on the scale below the risk level you would assign to Company X:

\begin{tabular}{ll}
\hline Riskless & Exceeds \\
& Maximum Risk \\
& Allowance
\end{tabular}

In a continuation of your investigation of Company $\mathrm{X}$ for a loan, you discover a potential loss contained in Company X's audited financial statements (including footnotes and an unqualified audit report). This contingent loss, which will affect the ability to repay, relates to pending litigation. The outcome from this litigation will be known in the upcoming year. However, the likelihood of losing this lawsuit is remote (reasonably possible, probable, $10 \%$ to $20 \%, 50 \%$ to $70 \%, 70 \%$ to $90 \%$ ).

Considering this new information along with the previous information about the company (i.e., superior Value Line financial strength measures, Z-score classification with healthy firms, industry not affected by recession, and financially strong), mark on the scale below the risk level you would now assign to Company $\mathrm{X}$, assuming you 
(d) Doubtful

\begin{tabular}{lllllllllll}
\hline $0 \%$ & 10 & 20 & 30 & 40 & 50 & 60 & 70 & 80 & 90 & $100 \%$
\end{tabular}

(e) High Probability

\begin{tabular}{lllllllllll}
\hline $0 \%$ & 10 & 20 & 30 & 40 & 50 & 60 & 70 & 80 & 90 & $100 \%$
\end{tabular}

(f) Remote

\begin{tabular}{lllllllllll}
\hline $0 \%$ & 10 & 20 & 30 & 40 & 50 & 60 & 70 & 80 & 90 & $100 \%$
\end{tabular}

(g) Likely

\begin{tabular}{lllllllllll}
\hline $0 \%$ & 10 & 20 & 30 & 40 & 50 & 60 & 70 & 80 & 90 & $100 \%$
\end{tabular}

(h) Certain

\begin{tabular}{lllllllllll}
\hline $0 \%$ & 10 & 20 & 30 & 40 & 50 & 60 & 70 & 80 & 90 & $100 \%$
\end{tabular}

(i) Perhaps

\begin{tabular}{lllllllllll}
\hline $0 \%$ & 10 & 20 & 30 & 40 & 50 & 60 & 70 & 80 & 90 & $100 \%$
\end{tabular}

(2) For each of the three verbal expressions listed, put a check next to the phrase that corresponds to the best definition for that verbal expression. (Check only one phrase for each verbal expression).

\section{Remote:}

An event (or events) is separated from others by a large interval.

The chance of the future event (or events) occurring is slight.

The degree of the future event (or events) is small.

An event (or events) that does not arise from a primary or proximate action.

An event (or events) that is far removed from others in space, time, or relation.

\section{Probable:}

An event (or events) is supported by evidence strong enough to establish presumption but not proof.

An event (or events) establishes a positive probability.

There is the likelihood of an event (or events) to be or become true or real.

The future event (or events) are likely to occur.

There is a reasonable ground for supposing an event (or events) will occur. 


\section{Reasonably Possible:}

An event (or events) that may or may not occur.

An event (or events) has an indicated potential.

The chance of the future event (or events) occurring is more than remote but less than likely.

The chance of an event (or events) is within the limits of ability, capacity, or realization.

It is likely that an event (or events) may be done or may occur according to nature.

(3) Risk Preference Assessment

There are two types of errors you, as lending officers, can make - (a) granting a loan to a customer who does not repay the loan, and (b) denying a loan to a customer who would have repaid the loan. Please mark on the scales below how concerned you are about these two errors.

(a) How concerned are you about making sure that you do not grant loans to customers who will never repay them?

\begin{tabular}{ll}
\hline Not at all & Extremely \\
Concerned & Concerned
\end{tabular}

(b) Compared to your concern about the error described in part (a) above (i.e., granting a loan that eventually defaults), how concerned are you about denying loans to customers who would have repaid them?

\begin{tabular}{lccccc}
\hline Much Less & Less & Equally & More & Much More \\
Concerned & \multicolumn{2}{c}{ Concerned } & Concerned & Concerned & Concerned \\
Than (a) & Than (a) & Than (a) & & Than (a) & Than (a)
\end{tabular}

(4) To the extent possible, please provide the following demographic information:
a) $\quad$ AGE
(b) GENDER:
MALE FEMALE

c) YEARS OF EXPERIENCE AS A COMMERCIAL LOAN OFFICER

d) AVERAGE NUMBER OF LOANS YOU PROCESS PER YEAR

e) TYPICAL DOLLAR AMOUNT OF LOAN PROCESSED BY YOU

f) EDUCATION LEVEL -- HIGHEST DEGREE EARNED

g) WHAT IS YOUR TITLE AT THE BANK 


\section{FOOTNOTES}

1. In this paper, the term "verbal" denotes an association with language or words, not a designation for oral communication.

2. A general definition is, "a membership function is a rule that assigns to each element in the universe of discourse a number in the closed $(0,1)$ interval indicating the degree to which that element is a member of a particular set or category" (Wallsten et al. 1986, 349).

3. While the resulting thresholds of other studies could have been utilized (i.e., Schultz and Reckers 1981; Jiambalvo and Wilner 1985; Harrison and Tomassini 1989), the Reimers' (1992) study appears to be the most comprehensive and well-controlled experiment.

4. Participants were asked in the instrument to measure their level of confidence in their risk assessments. Confidence levels for the two groups were reported on the 5-point scale as 3.0191 (verbal) and 3.0237 (numerical). Participant confidence was statistically unaffected by presentation mode.

\section{REFERENCES}

1. Armstrong, M. 1987. "Moral Development and Accounting Education.” Journal of Accounting Education 5: 27-43.

2. Asare, S. K. 1992. "The Auditor's Going Concern Decision: Interaction of Task Variables and the Sequential Processing of Evidence." The Accounting Review (April): 379-393.

3. Beaver, W. H. 1991. "Problems and Paradoxes in the Financial Reporting of Future Events." Accounting Horizons (December): 122-134.

4. Beyth-Maron, R. 1982. "How Probable is Probable? A Numerical Translation of Verbal Probability Expressions." Journal of Forecasting 1: 257-269.

5. Budescu, D. V., S. Weinberg, and T. S. Wallsten. 1988. "Decisions Based on Numerically and Verbally Expressed Uncertainties." Journal of Experimental Psychology: Human Perception and Performance 14 (May): 281-294.

6. Chang, C., S. Yen, and R. Duh. 2002. "An Empirical Examination of Competing Theories to Explain the Framing Effect in Accounting-Related Decisions." Behavioral Research in Accounting 14: 35-64.

7. Danos, P., D. L. Holt, and E. A. Imhoff. 1989. "The Use of Accounting Information in Bank Lending Decisions." Accounting, Organizations and Society 14: 235-246.

8. Deitrick, J. W., and J. L. Stamps. 1981. "The Use of Accounting Information by Bank Loan Officers." Journal of Commercial Bank Lending 64 (November): 51-62.

9. Dusenbury, R., and M. Fennema. 1996. "Linguistic - Numeric Presentation Mode Effects on Risky Option Preferences." Organization Behavior and Human Decision Processes. 68(2): 109-123.

10. Emby, C. 1994. "Framing and Presentation Mode Effects in Professional Judgment: Auditors' Internal Control Judgments and Substantive Testing Decisions." Auditing: A Journal of Practice and Theory 13 (Supplement): 102-115.

11. Financial Accounting Standards Board. 1975. Statement of Financial Accounting Standards No. 5: Accounting for Contingencies. Stamford, Conn.: FASB.

12. Hamm, R. M. 1991. "Selection of Verbal Probabilities: A Solution for Some Problems of Verbal Probability Expression." Organizational Behavior and Human Decision Processes 48 (April): 193-223.

13. Harrison, K. E., and L. A. Tomassini. 1989. "Judging the Probability of a Contingent Loss: An Empirical Study." Contemporary Accounting Research 5 (spring): 642-648.

14. Hogarth, R. M., and H. J. Einhorn. 1992. "Order Effects in Belief Updating: The Belief Adjustment Model.” Cognitive Psychology (January): 1-55.

15. Jamal, K., P. Johnson, and R. Berryman. 1995. "Detecting Framing Effects in Financial Statements." Contemporary Accounting Research 12 (fall): 85-105.

16. Jiambalvo, J., and N. Wilner. 1985. "Auditor Evaluation of Contingent Claims." Auditing: A Journal of Practice \& Theory 5 (fall): 1-11.

17. Kahneman, D., and A. Tversky. 1979. "Prospect Theory: An Analysis of Decisions Under Risk." Econometrica (March): 263-291. 
18. Kahneman, D., and A. Tversky. 1984. "Choices, Values and Frames.” American Psychologist (April): 341350 .

19. Kong, A., O. Barnett, F. Mosteller, and C. Youtz. 1986. "How Medical Professionals Evaluate Expressions of Probability." The New England Journal of Medicine 315 (September 18): 740-744.

20. Libby, R. 1979. "The Impact of Uncertainty Reporting on the Loan Decision." Journal of Accounting Research 17 (Supplement): 35-57.

21. Nakao, M. A., and S. Axelrod. 1983. "Numbers are Better Than Words." The American Journal of Medicine 74 (June): 1061-1065.

22. Nelson, M. and W. Kinney. 1997. "The Effect of Ambiguity on Loss Contingency Reporting Judgments." The Accounting Review (April): 257-275.

23. Raghunandan, K., R. A. Grimlund, and A. Schepanski. 1991. "Auditor Evaluation of Loss Contingencies." Contemporary Accounting Research (spring): 549-569.

24. Reimers, J. L. 1992. "Additional Evidence on the Need for Disclosure Reform." Accounting Horizons (March): 36-41.

25. Rest J. 1984. "The Major Component of Morality." In Morality, Moral Behavior, and Moral Development, edited by W. M. Kurtines, and J. L. Gerwirtz, 24-38. New York, NY: John Wiley and Sons.

26. Schultz, J. J., and P. M. J. Reckers. 1981. "The Impact of Group Processing on Selected Audit Disclosure Decisions." Journal of Accounting Research 19 (autumn): 482-501.

27. Simpson, R. H. 1944. "The Specific Meanings of Certain Terms Indicating Differing Degrees of Frequency." The Quarterly Journal of Speech 30 (October): 328-330.

28. Simpson, R. H. 1963. "Stability in Meanings for Quantitative Terms: A Comparison Over 20 Years." The Quarterly Journal of Speech 49 (April): 146-151.

29. Stocks, M., and B. Tuttle. 1998. "An Examination of Information Presentation Effects on Financial Distress Predictions." Advances in Accounting Information Systems 6: 107-128.

30. Tarek, A., K. Hackenbrack, and M. Nelson. 1994. "Between-Auditor Differences in the Interpretation of Probability Phrases." Auditing: A Journal of Practice and Theory 13 (spring): 126-137.

31. Teigen, K. H., and W. Brun. 1999. "The Directionality of Verbal Probability Expressions: Effects on Decisions, Predictions, and Probabilistic Reasoning." Organizational Behavior and Human Decision Processes 80 (November): 155-190.

32. Trotman, K. T., and J. Sng. 1989. "The Effect of Hypothesis Framing, Prior Expectations and Cue Diagnosticity on Auditors' Information Choice.” Accounting, Organizations and Society (December): 565576.

33. Tversky, A., and D. Kahneman. 1981. "The Framing of Decisions and the Rationality of Choice.” Science (January): 453-458.

34. Tversky, A., and D. Kahneman. 1986. "Rational Choice and the Framing of Decisions." Journal of Business (October): 251-278.

35. Wallsten, T. S., D. V. Budescu, A. Rapoport, R. Zwick, and B. Forsyth. 1986. "Measuring the Vague Meanings of Probability Terms." Journal of Experimental Psychology: General 115 (December): 348-365.

36. Zwick, R. 1987. "Combining Stochastic Uncertainty and Linguistic Inexactness: Theory and Experimental Evaluation." PhD. Dissertation, University of North Carolina, Chapel Hill. 